\title{
Effect of Social Media on Learning Effectiveness: Examining the mediating role of the Socialization, Externalization, Combination, Internalization and knowledge sharing
}

\author{
${ }^{1}$ R. Hemalatha, ${ }^{2}$ Dr. V. Lavanya, \& ${ }^{3}$ B. Karthick \\ ${ }^{1}$ Research Scholar, National Institute of Technology, Tiruchirappalli \\ ${ }^{2}$ Assistant Professor, National Institute of Technology, Tiruchirappalli \\ ${ }^{3}$ Research Scholar, Kongunadu Arts and Science College, Coimbatore
}

Article History: Received: 10 January 2021; Revised: 12 February 2021; Accepted: 27 March 2021; Published online: 10 May 2021

\begin{abstract}
With the advent of social media and its tools for knowledge sharing and effective learning. This study is intended to examine the mediating role of creation of new knowledge for effective learning and sharing. This study intended to investigate and map social media for effective learning through creation of new knowledge and tacit sharing requirements. With systematic review on the existing literature, found that Nonaka's knowledge spirals Socialization, Externalization, Combination, and Internalization as a mediator and how each contributes on effective learning through social media. This study has been conducted with a sample of 521 engineering and management students who are in the age of 18-34 years. This study uses the Survey technique and the data which was prepared based on the earlier studies on similar topics. The effect on knowledge sharing through social media which was constructed by Bock et., al 2005 has been used for measuring in this study. The mediating role of SECI on social media and knowledge sharing for effective learning has been assessed based on the four dimensions Socialization, Externalization, Combination, and Internalization multi-dimensional questionnaire offered by Nonaka et. al, (2000) has been used for this study. The results reveal which of the four dimensions of Nonaka 's, that, which has a significant impact on effective learning using social media \& knowledge sharing that has been brought to light from this study. The empirical findings of this study may enable to enrich the theoretical and practical implications.
\end{abstract}

Keywords: Social Media, Knowledge Sharing, Socialization, Externalization, Combination and Internalization, Effective learning.

\section{Introduction}

In this study we had taken upon key frameworks and models relevant to effective knowledge and knowledge sharing and synthesized it with learning and doing through a mediator role of Nonaka's SECI. In the course of the study, it has also been found that there exist serial mediations in these areas of: perceptive-sharing-learning, tacit -explicit knowledge in the knowledge spiral.

The motive of this paper is to come up with enhanced understanding on the concepts of learning-doing in higher education. In very recent times, the interesting concepts of sharing of knowledge and social interactions have been grown remarkably in both the academic and the business worlds. Understanding of knowledge is the source for competitive advantage and has been enhanced through varied frameworks for increasing knowledge-based views (Grant, 1996). Learning which happens, at the individual level, gets transferred to the higher level, and then it can be leveraged to achieve the goals and outcomes. Though there is a huge work in the connection between learning and performance, and it has been agreed by researchers that there exists a knowing-doing gap (Pfeffer \& Sutton 1999). It has also been absorbed by researchers that there are various factors looked in that moderate learning and performance relationships. In this study, we had identified a mediator which enables the relationship with learning $\&$ performance and identified that there exist serial mediations in this process.

\section{Background of the study}

The omnipresence of social media and the impact that it has created has attracted global attention (Yunis Ali Ahmed, Mohammad Nazir Ahmad, Nor Hidayati Zakaria (2019), Norasnita Ahmad). The intense development of social media has transformed knowledge sharing and the way of communicating and collaborating with people. ( $\underline{\mathrm{Li}}$ and Sakamoto, 2014; Filo et al., 2015). Social Networking, personal blogs or Twitter, Myspace and Facebook, 
microblogs, video-sharing applications like Flickr or YouTube, and other collaborative websites like Wikipedia (Osatuyi, 2013; Kaplan and Haenlein, 2010; Yan et al., 2013) which are the forums that are used for communicating and sharing information. These noticeable social media tools are entrenched spaces for creation of new knowledge sharing channels, where people may able to identify individuals of similar interests for sharing their thoughts with them (Bilgihan et al., 2016).

In today's competitive scenario's even higher educational institutions are also adopting social media as a mean for inspiring activities based on learning. (Kulakli and Mahony, 2014; Balakrishnan and Gan, 2016.

During the last few years, there has been researches that are indicating that there is a steady use of social media for sharing knowledge and it has increased the levels of attention. There are several aspects that signify the learning processes through knowledge that has been gained from the availability, influence \& creation of norms and beliefs, and power. In a study from Reagans and McEvily (2003) that network range and bonding that eases knowledge transfer.

Crossan et al. (1999) has provided a model for organizational learning in four stages. Nonaka (1994) had provided a spiral model for knowledge creation at organizations. In this study the author has attempted to integrate the models and presented them, in an integrated process model for learnings at higher educational institutions.

Crossan et als. (1999) 4Is are Intuiting, Integrating, Interpreting and Institutionalizing. These processes provided by him are bi-directional and involved both creation \& application of knowledge at various levels. This framework has been used here in this model. The challenges are, the model by Crossan et als. (1999) do not distinguishes explicitly the types of knowledge, while Nonaka (1994) model is dispenses between the tacit and explicit knowledge. Nonaka (1994) argued that in his "spiral", "It is the continuous interaction between tacit and explicit knowledge that drives new knowledge creation; where tacit knowledge is knowledge deeply rooted in action, commitment and is difficult to codify and explicit knowledge is knowledge that can be transmitted through formal language". Nonaka, also highlighted social interaction trait for knowledge creation.

Nonaka termed the fours modes of the knowledge conversion as "Tacit to Tacit - Socialization"; "Tacit to Explicit Externalization"; "Explicit to Explicit - Combination"; \& "Explicit to Tacit - Internalization".

We proposed that Nonaka's (1994) adaption of the 4I model helped in enhancing by satisfying the details between the four I-step, and linking the type of knowledge required at every stage. As Crossan et als. (1999) mention, "[T]he subconscious is critical to understanding how people come to discern and comprehend something new" (p.-526) from their experiences.

Nonaka (1994) categorized the process of conversions of individual tacit knowledge as group tacit knowledge and called it Socialization. The base from this enables perceiving, experience of the individual, may be taken as tacit knowledge. This intervening conversion through socialization helps in the next 4I process interprets, aiding the sharing of experiences.

The experiences shared through meaningful discussion may lead for conversion of group tacit knowledge to group explicit knowledge; and it is named as Externalization by Nonaka. This explicit knowledge that has been converted at this group level would nurture into the next level thereby integrating the $4 \mathrm{I}$.

The third step of integrating is a process for creating combined action of the group, through negotiations and alterations. This progresses for an in-depth understanding to the members through stories that are articulated and repeated.

Nonaka labelled that knowledge conversion practices, social processes for combining different bodies or group explicit knowledge as Combination and this group's explicit knowledge that is understood and shared in a more common way by giving examples through stories which is combined to make a role in the 4I process step, through common action suitably and by the way of understanding procedures. The shared feeds into the final step which institutionalize, where learning becomes entrenched at organizational memory (Walsh \& Ungson, 1991) through routines and structures. These process of an individual may makes things influential. This conversion of group explicit knowledge to individual tacit knowledge has been defined by Nonaka as Internalization. 
There are also various factors that may impact the effective applications of knowledge that includes social networks, information systems, \& culture (Alavi \& Leidner, 2001). Transfer of knowledge transfer may happen through formal/ informal ways (Alavi \& Leidner, 2001). Knowledge that has been transferred through best practice is formal (O’Dell \& Grayson, 1998).

Argote and Ingram (2000) refers that the process of moving knowledge pools as the virtue for transferring knowledge. Knowledge pools refer to knowledge that may be implanted in members, sub-networks, and in tools \& tasks.

Many of the researchers have looked at the various factors that render a relationship between learning and performance. Hislop 2005; has also discussed in his research work that only practice-based perceptions can hypothesizes knowledge as not as object which can be retrieved, codified and stored for future, but embedded in and inseparable from practice (Hislop, 2005). Every individual possesses incomplete and contradictory knowledge which may be in dispersed bits.

Every individual possesses incomplete and contradictory knowledge which may be in dispersed bits. Further to Polanyi's (1962) on the conception of tacit knowledge that he claimed "that there is always more to what can be explained and named this residual knowledge "tacit knowledge"" and in his work he has often articulated that the dichotomy between explicit and tacit knowledge, the perception of knowledge entitles that knowledge and learning are rooted in practice and constructed socially. Further to it Tsoukas refers this as, that Knowledge is multidisciplinary, it is distributed and fundamentally indeterminate.

The knowing perception claims that sharing knowledge or acquiring knowledge happens through "rich" social integration \& entanglement in practice - by the way of watching and/or doing (Hislop, 2005). Tsoukas (1996) states that in (p.-22): "Given the distributed character of organizational knowledge, the key to achieving coordinated action does not so much depend on those "higher up" collecting more and more knowledge, as on those "lower down" finding more and more ways of getting connected and interrelating the knowledge each one has". This is also more applicable to the higher educations as well.

\section{Hypothesis Development}

Here in this study we will examine the mediating role of Nonaka's four dimensional variables Socialization, Externalization, Combination, and Internalization on social media-learning effectiveness. The mediating effect of Nonaka's four dimensions Socialization, Externalization, Combination, and Internalization and networking plays a very important role and ease the process of sharing. Helping others may provide opportunity for growth and learning by Wasko and Faraj (2000) \& Ba et al. 2001. For creation of new knowledge, sharing of knowledge and effectiveness in learning, how social media acts as an enabler has led to the following hypothesis

H1: Impact of social media on knowledge sharing

H2: Impact of social media on learning effectiveness

H3: Impact of social media on socialization

H4: Impact of social media on externalization

H5: Impact of social media on combination

H6: Impact of social media on internalization

H7: Impact of socialization on knowledge sharing

H8: Impact of socialization on learning effectiveness

H9: Impact of Externalization on knowledge sharing

H10: Impact of Externalization on learning effectiveness

H11: Impact of combination on knowledge sharing

H12: Impact of combination on learning effectiveness

H13: Impact of internalization on knowledge sharing

H12: Impact of internalization on learning effectiveness 
Creation of new knowledge is a cyclic process and sharing of thoughts both tacit \& explicit between individual and group (Blackler, 1995; Nonaka \& Takeuchi, (1995), J. Bloodgood and W. Salisbury) were widely accepted on individual learning as well as in groups which enable sharing for creation of new knowledge and this paves way for the hypotheses below.

H13: The mediating role of Socialization, Externalization, Combination, and Internalization, on social media and learning effectiveness

H14: The mediating role of Socialization, Externalization, Combination, and Internalization, on social media and knowledge sharing leading to learning effectiveness

H15: The mediating role of knowledge sharing in social media and learning effectiveness

Ranjan and Khalil (2007, pp. 15-25); in their research they had a mention on how institutes can create a robust and flourishing knowledge in developing a culture on accessing, collaborating and managing knowledge. This leads to the hypothesis on how well higher educational institutions can work on effective learning influenced by creation of new knowledge. Rowley, 2000; Sohail and Daud, 2009, had also widely discussed that Universities were warehouse for knowledge generation and dissemination which lead to the above hypotheses.

Based on the above-mentioned hypotheses, the author has framed a conceptual model as seen in the Figure 1). From the model it has been observed that social media as independent and resilient students were able to utilize their skills and strengths using the mediator variables of SECI and the outcome variables are knowledge sharing and learning effectiveness 
Effect of Social Media on Learning Effectiveness: Examining the mediating role of the Socialization, Externalization, Combination, Internalization and knowledge sharing

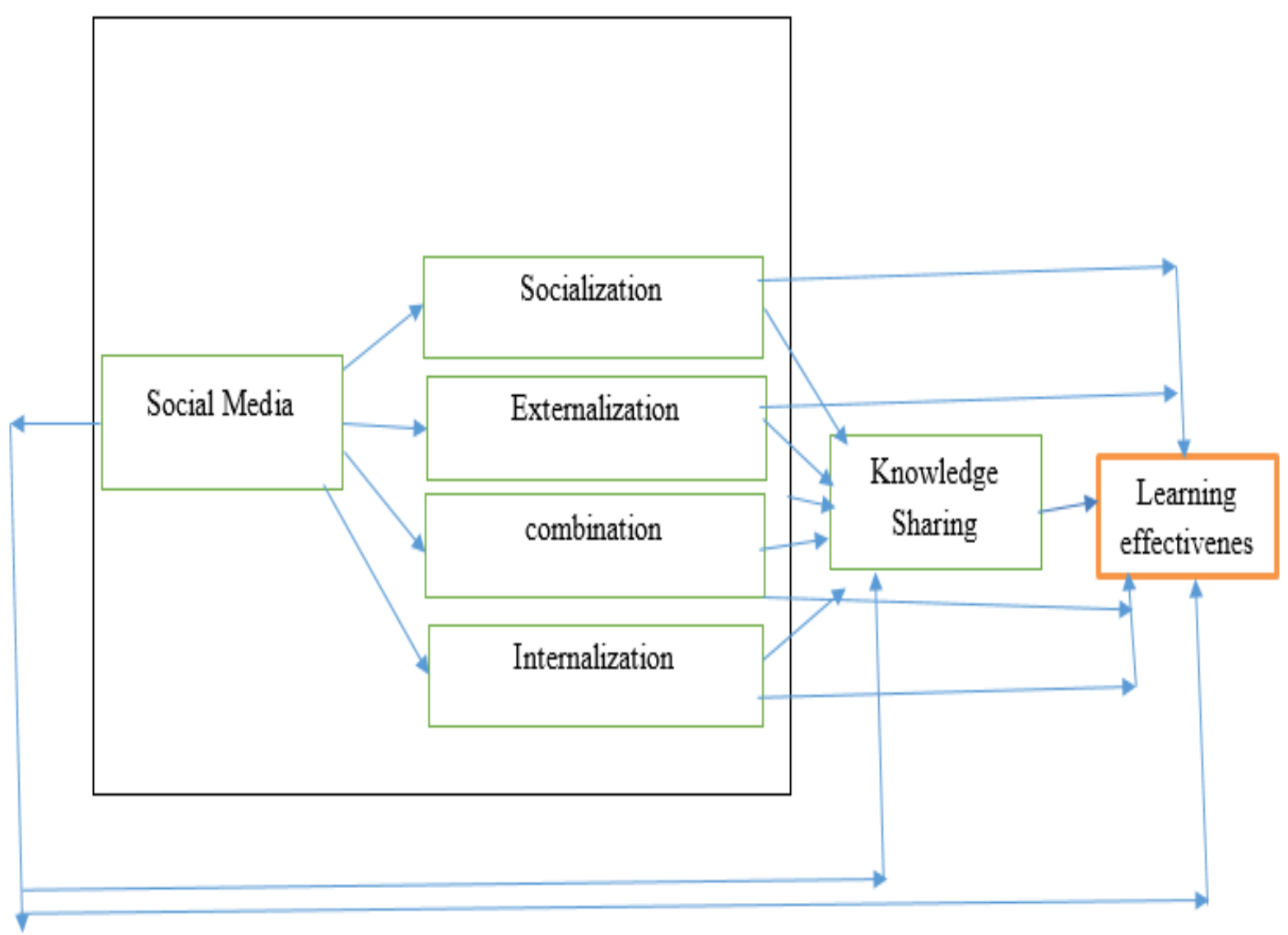

Figure 1. Model on the Relationship between Variables under this Study

\section{Procedure}

\section{Sample Population}

521 engineering and management students from National Institute of Technology and Indian Institute of Management Tiruchirappalli were taken for this study. Range of age 18-34 years were considered for this study. The sample consisted of $68.48 \%$ of male and $25.91 \%$ of female students.

\section{Measures}

In this study, we have revealed that in social media and Learning effectiveness, there has a mediation. It also has an indirect effect. The mediating variable may be endogenous and reveals more about it during the process. During the observation of the study, this has serial mediation also which has been identified by the items of the scale for the variables. The following are the standard tools that are used in this study. Professors and the research scholars tested the instrument's content validity.

\section{$\underline{\text { Research Instrument }}$}

Variables are measured using 5 point Likert scale and 7 point Likert scale. In the 5 point Likert scale, owing to, 5 represents strongly agree and 1 represents strongly disagree and in the 7 point Likert scale 7 representing very high 
and 1 representing very low. An initial pilot study has been conducted with 50 students and after that few alterations have been made with the scales.

Design of the study: This study is a descriptive study with a cross section design. Students of the higher educational institution were the target audience. Out of 600 collected questionnaires 521 questionnaires were considered for the study and eliminated 79 for discrepancies in the submitted data. Out of 521, $61.05 \%$ of them were in the age group of $18-24,68.48 \%$ of them were male students, $63.04 \%$ of them are in the under graduate levels, $80.05 \%$ of them uses social media for sharing knowledge. This study follows a cross sectional design with one independent variable and has more than one dependent variables which act as mediator for the other dependent variables. The population that is considered for the study was diversified and hence the results can be generalized to a bigger population.

Social Media: It was measured with the 5 point ranking scale which has 3 items on the scale. The validated reliability of the scale is 0.70

Nonakas' SECI (Socialization, Externalization Combination and Internalization): The attributes of the participants were measured on the ranking scale which has been constructed by Nonaka (1995). The scale contains 4 dimensions namely socialization, externalization, combination and internalization. 6 items on Socialization, 5 items on Externalization, 4 items on Combination and 5 items on Internalization. The reliability of the scales and the values for all the factors were above 0.6 to 0.9 .

Knowledge Sharing: Trait resilience was measured on knowledge sharing for the scale containing 6 scale items. The reliability was measured as 0.85 .

Learning Effectiveness: For assessing learning effectiveness, a scale of 4 has been used. The reported reliability for the scale is 0.76 for this study.

\section{Procedure}

Respondents were provided the questionnaire in a booklet related to the study, with a briefing by the researcher on the content and also the purpose trailing this study. Eventually, the participants were thanked for their participation and the respondents were assured that those responses provided by them will be kept confidential and it may be used only for the purpose of this academic research.

\section{Outcome}

The study used the Process Macros as it has been recommended by many researchers and suggested to conduct the mediation process (Hayes, 2017). Moreover, we have used process macro to understand the individual indirect path effects, and this will calculate it more straight forwardly than any other software.

Table 1: The table below presents the descriptive statistics of the scales and their reliability coefficients.

\begin{tabular}{|l|l|l|l|l|l|l|}
\hline Variables & Items & Population & Mean & $\begin{array}{l}\text { Standard } \\
\text { Deviation }\end{array}$ & $\begin{array}{l}\text { Standard } \\
\text { Loading }\end{array}$ & $\begin{array}{l}\text { Reliability } \\
\text { (Alpha) }\end{array}$ \\
\hline Social Media & 3 & 521 & 4.87 & 1.17 & 0.73 & 0.70 \\
\hline Socialization & 6 & 521 & 5.33 & 1.23 & 0.83 & 0.81 \\
\hline Externalization & 4 & 521 & 5.12 & 1.22 & 0.85 & 0.78 \\
\hline Combination & 4 & 521 & 4.84 & 1.19 & 0.76 & 0.78 \\
\hline Internalization & 5 & 521 & 4.73 & 1.25 & 0.86 & 0.82 \\
\hline
\end{tabular}


Effect of Social Media on Learning Effectiveness: Examining the mediating role of the Socialization,

Externalization, Combination, Internalization and knowledge sharing

\begin{tabular}{|l|l|l|l|l|l|l|}
\hline Knowledge Sharing & 6 & 521 & 5.55 & 1.56 & 0.82 & 0.85 \\
\hline $\begin{array}{l}\text { Learning } \\
\text { Effectiveness }\end{array}$ & 4 & 521 & 5.34 & 1.31 & 0.80 & 0.76 \\
\hline
\end{tabular}

Analysis on mediating role of SECIs Socialization, Externalization, Combination, Internalization \& Knowledge sharing between social media and learning effectiveness.

There exists a positive regression which concludes that there exists mediation during the process. Hence in this study the author explored with the SPSS process macros to identify the mediating effect between the independent and the dependent variable.

From the table below, the confidence intervals from the measured output is 95.0000 and the bootstrap confidence interval from the samples considered is 5000 .

Table 2:

Run MATRIX procedure:

**************** PROCESS Procedure for SPSS Version 3.2.01 ******************

Written by Andrew F. Hayes, Ph.D. www.afhayes.com

Documentation available in Hayes (2018). www.guilford.com/p/hayes3

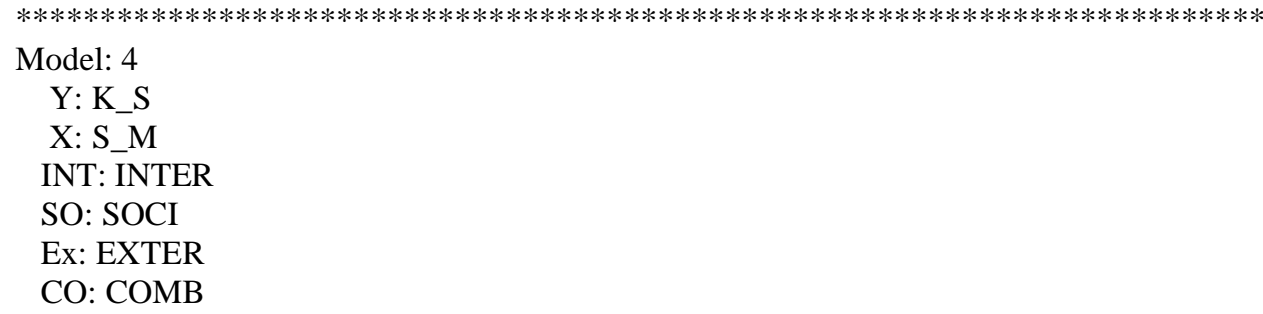

Sample

Size: 521

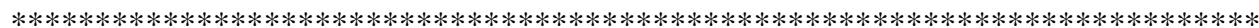

OUTCOME VARIABLE:

INTER

Model Summary

$\begin{array}{cccccccr}\mathrm{R} & \mathrm{R}-\mathrm{sq} . & \mathrm{MSE} & \mathrm{F} & \mathrm{df1} & \mathrm{df} 2 & \mathrm{p} & \\ .4190 & .1756 & .8266 & 82.1918 & 1.0000 & 386.0000 & .0000\end{array}$

Model

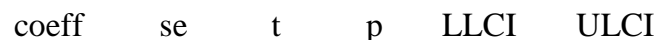

$\begin{array}{lllllll}\text { constant } & .0000 & .0462 & .0000 & 1.0000 & -.0907 & .0907\end{array}$

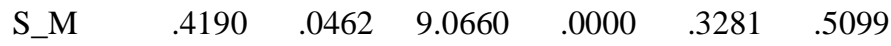

*************************************************************************************

OUTCOME VARIABLE:

SOCI

Model Summary 
$\begin{array}{cccccccc}\mathrm{R} & \mathrm{R}-\mathrm{sq} . & \mathrm{MSE} & \mathrm{F} & \mathrm{df1} & \mathrm{df} 2 & \mathrm{p} & \\ .1984 & .0394 & .9631 & 15.8232 & 1.0000 & 386.0000 & .0001\end{array}$

Model

\begin{tabular}{lcccccc}
\multicolumn{2}{c}{ coeff } & se & $\mathrm{t}$ & $\mathrm{p}$ & LLCI & ULCI \\
constant & .0000 & .0498 & .0000 & 1.0000 & -.0980 & .0980 \\
S_M & .1984 & .0499 & 3.9778 & .0001 & .1004 & .2965
\end{tabular}

$* * * * * * * * * * * * * * * * * * * * * * * * * * * * * * * * * * * * * * * * * * * * * * * * * * * * * * * * * * * * * * * * * * * * * * * * * *$

OUTCOME VARIABLE:

EXTER

Model Summary

$\begin{array}{cccccccc}\mathrm{R} & \text { R-sq. } & \text { MSE } & \mathrm{F} & \mathrm{df1} & \mathrm{df} 2 & \mathrm{p} & \\ .4194 & .1759 & .8262 & 82.4081 & 1.0000 & 386.0000 & .0000\end{array}$

Model

\begin{tabular}{lrrrrrr}
\multicolumn{2}{c}{ coeff } & se & $\mathrm{t}$ & $\mathrm{p}$ & LLCI & ULCI \\
constant & .0000 & .0461 & .0000 & 1.0000 & -.0907 & .0907 \\
S_M & .4194 & .0462 & 9.0779 & .0000 & .3286 & .5103
\end{tabular}

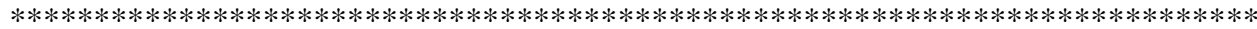

OUTCOME VARIABLE:

COMB

Model Summary

$\begin{array}{cccccccr}\mathrm{R} & \mathrm{R}-\mathrm{sq} . & \mathrm{MSE} & \mathrm{F} & \mathrm{df} 1 & \mathrm{df} 2 & \mathrm{p} & \\ .2729 & .0745 & .9279 & 31.0578 & 1.0000 & 386.0000 & .0000\end{array}$

Model

\begin{tabular}{lrrrrrr}
\multicolumn{2}{c}{ coeff } & $\mathrm{se}$ & $\mathrm{t}$ & $\mathrm{p}$ & LLCI & ULCI \\
constant & .0000 & .0489 & .0000 & 1.0000 & -.0962 & .0962 \\
S_M & .2729 & .0490 & 5.5730 & .0000 & .1766 & .3692
\end{tabular}

************************************************************************************

OUTCOME VARIABLE:

K_S

Model Summary

R R-sq. MSE $\mathrm{F} \quad \mathrm{df} 1 \quad \mathrm{df} 2 \quad \mathrm{p}$

$\begin{array}{lllllll}.7380 & .5447 & .4613 & 91.4011 & 5.0000 & 382.0000 & .0000\end{array}$

Model

\begin{tabular}{lcccccc}
\multicolumn{2}{c}{ coeff } & $\mathrm{se}$ & $\mathrm{t}$ & $\mathrm{p}$ & LLCI & ULCI \\
constant & .0000 & .0345 & .0000 & 1.0000 & -.0678 & .0678 \\
S_M & .1516 & .0400 & 3.7885 & .0002 & .0729 & .2303 \\
INTER & .1521 & .0410 & 3.7136 & .0002 & .0716 & .2326 \\
SOCI & .0853 & .0365 & 2.3385 & .0199 & .0136 & .1570 \\
EXTER & .2401 & .0426 & 5.6306 & .0000 & .1563 & .3240 \\
COMB & .3834 & .0415 & 9.2326 & .0000 & .3017 & .4650
\end{tabular}

****************** DIRECT AND INDIRECT EFFECTS OF X ON Y $* * * * * * * * * * * * * * * * *$

Direct effect of $\mathrm{X}$ on $\mathrm{Y}$
Effect
se
$\begin{array}{llllll}.1516 & .0400 & 3.7885 & .0002 & .0729 & .2303\end{array}$ 
Effect of Social Media on Learning Effectiveness: Examining the mediating role of the Socialization,

Externalization, Combination, Internalization and knowledge sharing

Indirect effect(s) of $\mathrm{X}$ on $\mathrm{Y}$ :

Effect BootSE BootLLCI BootULCI

$\begin{array}{lcccc}\text { TOTAL } & .2860 & .0542 & .1857 & .3954 \\ \text { INTER } & .0637 & .0215 & .0244 & .1095 \\ \text { SOCI } & .0169 & .0088 & .0028 & .0366 \\ \text { EXTER } & .1007 & .0289 & .0521 & .1645 \\ \text { COMB } & .1046 & .0292 & .0518 & .1654\end{array}$

$* * * * * * * * * * * * * * * * * * * * * * *$ ANALYSIS NOTES AND ERRORS $* * * * * * * * * * * * * * * * * * * * * * * *$

To test hypothesis through mediating variable and establishing relationship between independent and dependent variables, it is required to show that there is an existence of a direct effect which has mediation, with the first step of the analysis that involves regressing as detailed in Table 2 that $\mathrm{R}$ is positive and is more significant as per the analysis and there exists a mediation in the study. The table 3 below confirms the validity and reliability of the variables.

Table 3:

\begin{tabular}{|ll|l|r|r|r|l|l|l|l|l|l|}
\hline \multicolumn{2}{|c|}{ CR } & \multicolumn{1}{l|}{ AVE } & \multicolumn{1}{l|}{ MSV } & MaxR(H) & LEF & KS & INT & CO & SO & EX & SM \\
\hline LEF & 0.848 & 0.583 & 0.377 & 0.853 & $\mathbf{0 . 7 6 4}$ & & & & & & \\
\hline KS & 0.916 & 0.645 & 0.25 & 0.918 & 0.5 & $\mathbf{0 . 8 0 3}$ & & & & & \\
\hline INT & 0.943 & 0.769 & 0.285 & 0.965 & 0.369 & 0.226 & $\mathbf{0 . 8 7 7}$ & & & & \\
\hline CO & 0.849 & 0.587 & 0.514 & 0.875 & 0.495 & 0.289 & 0.469 & $\mathbf{0 . 7 6 6}$ & & & \\
\hline SO & 0.932 & 0.695 & 0.514 & 0.936 & 0.614 & 0.348 & 0.521 & 0.717 & $\mathbf{0 . 8 3 4}$ & & \\
\hline EX & 0.869 & 0.625 & 0.448 & 0.894 & 0.496 & 0.295 & 0.449 & 0.613 & 0.669 & $\mathbf{0 . 7 9 1}$ & \\
\hline SM & 0.907 & 0.767 & 0.285 & 0.958 & 0.379 & 0.229 & 0.534 & 0.367 & 0.52 & 0.443 & $\mathbf{0 . 8 7 6}$ \\
\hline
\end{tabular}

The inferences for the hypothesis may be understood from the tables below for the Direct and indirect effect of the variables which are detailed.

Table 4:

\begin{tabular}{|l|l|l|l|r|r|r|r|l|}
\hline Hypothesis & Direct Path & \multicolumn{1}{|c|}{ coeff } & se & t-Value & $\begin{array}{c}\text { V- } \\
\text { Value }\end{array}$ & LLCI & ULCI & Hypothesis Results \\
\hline H1 & SM->Int & 0.419 & 0.0462 & 9.066 & 0.00 & 0.3281 & 0.5099 & Supported \\
\hline H2 & SM->SOCI & 0.1984 & 0.0499 & 3.9778 & 0.00 & 0.1004 & 0.2965 & Supported \\
\hline H3 & SM->EXT & 0.4194 & 0.0462 & 9.0779 & 0.00 & 0.3286 & 0.5103 & Supported \\
\hline H4 & SM->COMB & 0.2729 & 0.049 & 5.573 & 0.00 & 0.1766 & 0.3692 & Supported \\
\hline H5 & SM->KS & 0.1516 & 0.04 & 3.7885 & 0.00 & 0.0729 & 0.2303 & Supported \\
\hline H6 & SM->LE & 0.0606 & 0.0458 & 1.3217 & 0.19 & -0.0295 & 0.1507 & Not Supported \\
\hline H7 & INT->KS & 0.1521 & 0.041 & 3.7136 & 0.00 & 0.0716 & 0.2326 & Supported \\
\hline H8 & SOCI->KS & 0.0853 & 0.0365 & 2.3385 & 0.02 & 0.0136 & 0.157 & Supported \\
\hline H9 & EXTER->KS & 0.2401 & 0.0426 & 5.6306 & 0.00 & 0.1563 & 0.324 & Supported \\
\hline
\end{tabular}




\begin{tabular}{|l|l|r|r|r|r|r|r|l|}
\hline H10 & COMB->KS & 0.3834 & 0.0415 & 9.2326 & 0.00 & 0.3017 & 0.465 & Supported \\
\hline H11 & INT->LE & 0.0693 & 0.0469 & 1.478 & 0.14 & -0.0229 & 0.1615 & Not Supported \\
\hline H12 & SOCI->LE & 0.3328 & 0.0413 & 8.0567 & 0.00 & 0.2516 & 0.414 & Supported \\
\hline H13 & EXT->LE & 0.1078 & 0.0499 & 2.1599 & 0.03 & 0.0097 & 0.206 & Supported \\
\hline H14 & COMB->LE & 0.1049 & 0.0516 & 2.0309 & 0.04 & 0.0033 & 0.2064 & Supported \\
\hline H15 & KS->LE & 0.236 & 0.0575 & 4.1016 & 0.00 & 0.1229 & 0.3492 & Supported \\
\hline
\end{tabular}

Table 5:

\begin{tabular}{|l|l|r|r|r|r|l|}
\hline Hypothesis & Indirect Effect & Effect & BootSE & BootLLCI & BootULCI & Hypothesis Results \\
\hline & SM->INT->LE & 0.029 & 0.0208 & -0.0099 & 0.073 & Not Supported \\
\hline & SM->SOCI-> LE & 0.066 & 0.0225 & 0.0279 & 0.1148 & Supported \\
\hline & SM->EXT-> LE & 0.0452 & 0.0235 & 0.004 & 0.096 & Supported \\
\hline & SM->COMB->LE & 0.0286 & 0.018 & -0.0017 & 0.0687 & Not Supported \\
\hline & SM->KS->LE & 0.0358 & 0.0147 & 0.011 & 0.0679 & Supported \\
\hline & SM->INT->KS->LE & 0.015 & 0.0068 & 0.0048 & 0.0308 & Supported \\
\hline & SM->SOCI->KS->LE & 0.004 & 0.0026 & 0.0005 & 0.0107 & Supported \\
\hline & SM->EXT->KS->LE & 0.0238 & 0.0096 & 0.0088 & 0.0455 & Supported \\
\hline & SM->COMB->KS->LE & 0.0247 & 0.0094 & 0.0092 & 0.0456 & Supported \\
\hline
\end{tabular}

From the results tabulated above social media on learning effectiveness do not have any direct effect and was not supported. Though the value of $\mathrm{p}<.05$ for the $95 \%$ confidence interval for all the scales, LLCI and ULCI for social media and learning effectiveness and for Internalization and learning effectiveness was not supported as this has the values $[-0.0295,0.1507]$ and $[-0.0229,0.1615]$. From the table 4 results Social media do not have any direct impact on effective learning, whereas social media contributes for tacit and explicit knowledge sharing. Knowledge sharing, dissemination of knowledge and effective learning happens. Hence H1 to H12 was supported except $\mathrm{H} 2$ and $\mathrm{H} 12$

Adding on to the causal approach, this study was conducted to express in respect to the significance of Nonaka's (SECI socialization, externalization, combination, internalization and knowledge sharing) knowledge creation process that paves way for social media on learning effectiveness. The study determines the importance of the indirect effect of the mediator for testing the hypothesis which has a significant difference between the total effect and the direct effect. The indirect effect of the mediator is the product of the path which is equivalent to direct effect and indirect effect. The results of this study confirm that there exists a mediating effect in the relationship.

To evaluate the presence of mediation and to examine the true indirect effects of Social Media on Learning Effectiveness via socialization, externalization, combination and Internalization (Nonaka's SECI), bias-corrected bootstrapping was used by the recommendations of HAYES, A. F. 2017 \& PREACHER, K. J. \& HAYES, A. F. (2004). Indirect effect of social media on learning effectiveness via socialization and externalization were entirely above zero for 95\% Confidence Interval (CI) lower limit (LL): 0.0279 and 0.004 \& upper limit (UL): 0.096 and 0.096 and hence H13 is partially supported for socialization and externalization. However, the indirect effect of social media on learning effectiveness via internalization and combination were not above zero for the $95 \%$ Confidence Interval (CI) lower limit (LL): -0.0099 and $-0.0017 \&$ upper limit (UL): 0.073 and 0.0687 and hence $\mathrm{H} 13$ is partially not supported for internalization and combination.

Thus, it confirms from the results of the four-step mediation analysis, provide evidences for partial mediation. 
Effect of Social Media on Learning Effectiveness: Examining the mediating role of the Socialization, Externalization, Combination, Internalization and knowledge sharing

Thus it confirms from the Table 5 that partial mediation effect of Social media on socialization/ externalization/ combination/ internalization on knowledge sharing and learning effectiveness is a well-being relationship. Thus it is evident from the results that four-step mediation analysis provide evidence for partial mediation and hence the hypothesis H14 is supported.

From the table that there is a medial relationship on social media and learning effectiveness via knowledge sharing and hence hypothesis H15.

The results presented in Table 4 \& Table 5 clearly indicates that social media is significantly and positively related to learning effectiveness only through mediator support and serial mediation in indirect effect, whereas social media do not have any impact on effective learning in direct effect. Hence Nonaka's socialization and externalization are a perfect mediator in the relationship of social media and learning effectiveness.

\section{Discussion}

The influence of social media on learning effectiveness (Barton, Adams, Browne \& Arrastia (2018), Mughahed, Shahizan, Mi, Alhaji (2015), Bicen and Saidkoglu, Chou and Liu (2005)), social media on knowledge sharing (Pee (2018)), social media on knowledge creation (Anna Lyude (2007), Mauroner (2016)), knowledge creation on knowledge sharing (Amine, Klamma, Jarke and Naeve (2007), Akhaven \& Abdali (2012)), Panahi, Watson and partridge (2013)) knowledge creation on learning effectiveness (Akhaven, Ramezan \& yazdi (2014), Berraies, Chaher \& Yahia (2014)), knowledge sharing and learning effectiveness (Iqbal and Latif (2018), Li-Wei Wu and Jwu-Rong Lin (2012) has been often discussed and studied. In addition, the influence of SECI has also been documented (Nonaka \& Takeuchi, 1995; Nonaka et al., 2008); But the mediating role of socialization, externalization, combination and internalization in the social media, learning effectiveness has very scant studies in higher educational institutions. Furthermore, the present study is to understand the driving relationship between social media, socialization, externalization, combination, internalization, knowledge sharing and learning effectiveness. Further the analysis indicates a causal relationship with social media and knowledge sharing also has a causal relationship with social media and Nonaka's four dimensional variables (SECI). Thus it may be assumed that levels of positive affect may depend on the extent of knowledge creation, knowledge sharing and learning effectiveness. Further, social media, knowledge creation and knowledge sharing will predict the level of effective learning. It can be inferred that socialization and externalization might act as a mediator in the relationship of social media with learning effectiveness based on the causal relationship of the variables. Using Baron and Kenny's approach, it has been observed that there exists a partial mediation. Thus it can be assumed to a greater extent that, the creation of new knowledge regulates the capacity and to maintain positive affect and lead towards to knowledge sharing and learning effectiveness. The higher the levels of knowledge creation, higher the tendency to find effective learning through shared knowledge. Such creations of new knowledge characterize knowledge sharing which further leads to learning effectiveness. In other words knowledge creation and knowledge sharing may lead to effective learning via social media.

\section{Imputations}

This research makes an effort to intend on mediating role of knowledge creation in the interconnection between social media and effective learning. During this course of study, it has been observed that there is serial mediation on social media on learning effectiveness. This may help to identify and found that both socialization, externalization and also knowledge sharing as determinants of social media and effective learning. There are very scant studies on the mediation analysis on the impact of SECI on social media and learning effectiveness in the academic area on higher educational institutions. Hence this study can yield valuable insights for further researches and can identify, also, new techniques could be discovered to develop the role of social media on effective learning through creation and distribution of new knowledge in the present day learnings.

\section{Limitations}


A major limitation in this study is the study was conducted on a centrally funded institution. hence, these results could not be generalized for a diverse population. Hither a larger diverse sample may lead to better conclusion regarding the mediating role of knowledge creation and knowledge sharing in the relationship with social media and learning effectiveness. In addition, this study is survey-based, whereas an additional experimental study and their findings may provide confidences during the conclusions.

\section{Conclusion}

The results of this study demonstrate that the creation of new knowledge and sharing leading to effective learning. Furthermore, the study indicates the importance of socialization and externalization in SECIs four dimensioned variables which act as a powerful mediator in the relationship, and hence there is a transformation of tacit to explicit knowledge happens during this course of the study. Therefore, it could be assumed that the more resilient wherein information can be interpreted in such a manner to become knowledge, and by maintaining positivity, which may further lead to effective learning.

\section{References}

Yunis Ali Ahmed, Mohammad Nazir Ahmad, Norasnita Ahmad, Nor Hidayati Zakaria (2019), Social media for knowledge-sharing: A systematic literature review, Telematics and Informatics 37 (2019) 72-112, https://doi.org/10.1016/j.tele.2018.01.015.

Filo, K., Lock, D., Karg, A., 2015. Sport and social media research: a review. Sport Manage. Rev. 18 (2), $166-181$.

Li, H., Sakamoto, Y., 2014. Social impacts in social media: an examination of perceived truthfulness and sharing of information. Comput. Hum. Behav. 41, 278-287.

Kaplan, A.M., Haenlein, M., 2010. Users of the world, unite! The challenges and opportunities of social media. Bus. Horiz. 53 (1), 59-68.

Osatuyi, B., 2013. Information sharing on social media sites. Comput. Hum. Behav. 29 (6), 2622-2631.

Yan, Y., Davison, R.M., Mo, C., 2013. Employee creativity formation: the roles of knowledge seeking, knowledge contributing and flow experience in Web 2.0 virtual communities. Comput. Hum. Behav. 29 (5), 1923-1932.

Yan, Z., Wang, T., Chen, Y., Zhang, H., 2016. Knowledge sharing in online health communities: a social exchange theory perspective. Inf. Manage. 53 (5), 643-653.

Bilgihan, A., Peng, C., Kandampully, J., 2014. Generation Y's dining information seeking and sharing behavior on social networking sites: an exploratory study. Int. J.Contemp. Hosp. Manage. 26 (3), 349-366.

Bilgihan, A., Barreda, A., Okumus, F., Nusair, K., 2016. Consumer perception of knowledge-sharing in travelrelated online social networks. Tourism Manage. 52, 287-296.

Balakrishnan, V., Gan, C.L., 2016. Students' learning styles and their effects on the use of social media technology for learning. Telematics Inform. 33 (3), 808-821. 
Effect of Social Media on Learning Effectiveness: Examining the mediating role of the Socialization, Externalization, Combination, Internalization and knowledge sharing

Kulakli, A., Mahony, S., 2014. knowledge creation and sharing with web 2.0 tools for teaching and learning roles in so-called university 2.0. Procedia Soc. Behav. Sci.150, 648-657.

Fatma Ozmen ${ }^{\text {a }} * 2010$, The capabilities of the educational organizations in making use of tacit knowledge, Procedia Social and Behavioral Sciences 9 (2010) 1860-1865.

Reagans, R., \& McEvily, B. (2003). Network structure and knowledge transfer: The effects of cohesion and range. Administrative Science Quarterly, 48, 240-267. doi:10.2307/3556658.

Pfeffer, J., \& Sutton, R. (1999). Knowing what to do is not enough. California Management Review, 42(1), 83108. doi: $10.2307 / 41166020$

Alavi, M., \& Leidner, D. E. (2001). KM and KM systems: Conceptual foundation and research issues. Management Information Systems Quarterly, 25(1), 107-136. doi:10.2307/3250961.

Argote, L., \& Ingram, P. (2000). Knowledge transfer: A basis for competitive advantage in firms. Organizational Behavior and Human Decision Processes, 82(1), 150-169. doi:10.1006/ obhd.2000.2893.

O’Dell, C., \& Grayson, C. J. (1998). If only we knew what we know. California Management Review, 40(3), 154-174. doi:10.2307/41165948.

SECI, Ba and Leadership: a Unified Model of Dynamic Knowledge Creation, Ikujiro Nonaka, Ryoko Toyama and Noboru Konno, Long Range Planning $33 \quad$ (2000) 5-34, www.elsevier.com/locate/lrp

Hislop, D. (2005). Knowledge management in organizations: A critical introduction. Oxford, UK: Oxford University Press.

Easterby-Smith, M., \& Lyles, M. A. (2003). Introduction: Watersheds of organizational learning and knowledge management. In M. Easterby-Smith, \& M. A. Lyles (Eds.), The Blackwell handbook of organizational learning and knowledge management. Oxford, UK: Wiley-Blackwell.

Polanyi, M. (1962). Personal knowledge. Chicago, IL: Chicago University Press.

Tsoukas, H. (1996). The firm as a distributed knowledge system. Strategic Management Journal, 17, 11-25.

PREACHER, K. J. \& HAYES, A. F. 2004. SPSS and SAS procedures for estimating indirect effects in simple mediation models. Behavior research methods, instruments, \& computers, 36, 717- 731.

HAYES, A. F. 2009. Beyond Baron and Kenny: Statistical mediation analysis in the new millennium. Communication monographs, 76, 408-420.

HAYES, A. F. 2017. Introduction to mediation, moderation, and conditional process analysis: A regression-based approach.

The effects of social media usage on attention, motivation, and academic performance, Bianca A Barton, Katharine $\underline{\text { S Adams, }}$ Blaine L Browne, ... , June 20, 2018 Research, article https://doi.org/10.1177/1469787418782817 